\title{
As perspectivas de estudantes ao final da escolarização básica sobre suas experiências nas aulas de educação física
}

\author{
Students' perspectives at the end of basic schooling \\ about their experiences in physical education classes
}

\section{Perspectivas de los estudiantes al final de la formación básica sobre sus experiencias en clases de educación física}

\author{
iD Simone Santos Kuhn \\ Universidade Federal do Rio Grande do Sul, Porto Alegre, Rio Grande do Sul, Brasil \\ simonesantosk@gmail.com \\ (1D) Lisandra Oliveira e Silva \\ Universidade Federal do Rio Grande do Sul, Porto Alegre, Rio Grande do Sul, Brasil \\ lisgba@yahoo.com.br \\ iD Vicente Molina Neto \\ Universidade Federal do Rio Grande do Sul, Porto Alegre, Rio Grande do Sul, Brasil \\ 00006808@ufrgs.br
}

\begin{abstract}
Resumo: A investigação objetivou compreender os significados atribuídos por estudantes do Terceiro Ano do Ensino Médio (EM) às suas experiências nas aulas de Educação Física (EF) durante a Educação Básica. Construímos os conhecimentos por meio da análise de documentos, da observação participante, dos diários de campo e do grupo de discussão. Analisamos e discutimos os conteúdos aprendidos nas aulas de EF, os significados da EF escolar e as relações com a vida cotidiana, bem como intentamos compreender essas aulas como espaço de relações interpessoais. O diálogo e os vínculos nas aulas de EF foram considerados
\end{abstract}

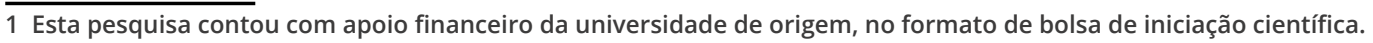


fundamentais para que os conteúdos fossem mais interessantes e mais significativos.

Palavras-chave: Educação Física Escolar. Perspectiva dos Estudantes. Grupo de Discussão.

Abstract: The research aimed to understand the significance Third Year High School (HS) students attributed to their experiences in Physical Education (PE) classes during Basic Education. We build knowledge through document analysis, participant observation, field diaries and the discussion group. We analyse and discuss the content learned in PE classes, the significance of school PE and its relationships with daily life, and PE classes as a space for interpersonal relationships. Dialogue and links in PE classes were considered key to making the content more interesting and meaningful.

Keywords: School Physical Education. Students' Perspective. Discussion Group.

Resumen: La investigación tenía como objetivo comprender los significados atribuidos por los estudiantes del Tercer Año de la Enseñanza Media (EM) a sus experiencias en las clases de Educación Física (EF) durante la Educación Básica. Desarrollamos conocimiento a través del análisis de documentos, de la observación participante, de diarios de campo y de grupos de debate. Analizamos y discutimos los contenidos aprendidos en las clases de EF, los significados de la EF en la escuela y las relaciones con la vida diaria, y las clases de EF como un espacio de relaciones interpersonales. El diálogo y los vínculos en las clases de educación física se consideraron clave para hacer que los contenidos sean más interesante y significativos.

Palabras clave: Educación Física Escolar. Perspectiva de los estudiantes. Grupo de debate. 


\section{Considerações Introdutórias}

Para Silva e Molina Neto (2014, p. 1154), “[...] a EF, na atualidade, vem constituindo-se componente curricular na escola, sendo percebida como espaço capaz de insuflar discussões que sugerem uma busca de sentido, outrora preenchido pela atividade física e a prática hegemônica do esporte". Nesse contexto de constantes transformações e disputas no campo curricular, entre os atores envolvidos nesse processo, destacamos a importância da participação dos estudantes, o que acreditamos ser fundamental para o enriquecimento das discussões sobre o papel da EF na escola.

Dayrell e Carrano (2014), ao abordarem o tema do protagonismo juvenil na escola, afirmam que:

[...] o engajamento participativo pode aumentar seu estímulo para novas aprendizagens, melhorar a escrita e provocar o desenvolvimento da capacidade de argumentação para a defesa de pontos de vista. Nesse sentido, a participação pode ser entendida como um processo educativo que potencializa os processos de aprendizagem no interior da escola. E, da mesma forma, pode contribuir para a constituição de amplos processos formativos (DAYRELL; CARRANO, 2014, p. 21).

Entretanto, esses autores criticam a tendência dos gestores educacionais de não considerarem os jovens como interlocutores válidos para a tomada de decisões importantes nas instituições. Muitas vezes, eles não são chamados para emitir opiniões, nem mesmo nas questões que lhes dizem respeito diretamente, o que pode ser considerado um desestímulo à sua participação e ao protagonismo nos processos de escolarização (DAYRELL; CARRANO, 2014).

Semelhante a isso, nas Políticas Públicas destinadas aos jovens nas últimas décadas, percebe-se maior preocupação em oferecer o que se intuiu como suas necessidades, do que em provocar processos que abrissem espaços e tempos de diálogo para que os 
As perspectivas de estudantes ao final da escolarização básica...

Simone Santos Kuhn • Lisandra Oliveira e Silva • Vicente Molina Neto

próprios jovens apontassem caminhos e demandas. No entanto, os jovens precisam de espaços e de tempos, não apenas para que recebam projetos preconcebidos por lógicas adultas, mas para que digam do que precisam e sinalizem para o que podem fazer individual e coletivamente. (CARRANO, 2012).

A partir disso, nesta pesquisa, propusemos um olhar que valorizasse as experiências e as percepções dos estudantes sobre o próprio aprendizado e sobre a EF no contexto escolar. Assim, partimos da seguinte questão de pesquisa: quais os significados atribuídos por estudantes do terceiro ano do EM às suas experiências nas aulas de EF durante a Educação Básica?

Desse modo, o objetivo geral trata de compreender os significados atribuídos por estudantes do terceiro ano do EM às suas experiências nas aulas de EF durante a Educação Básica, e os objetivos específicos são: identificar os conhecimentos aprendidos pelos estudantes do terceiro ano do EM nas aulas de EF durante a Educação Básica e compreender como esses conhecimentos se relacionam com suas vidas dentro e fora da escola.

\section{Decisões Metodológicas}

Trata de uma pesquisa de abordagem qualitativa, na qual a base da investigação está centrada na descrição, na análise, na interpretação e na discussão de informações que são obtidas no decorrer de um processo de investigação, não sendo possível fazer generalizações, mas um entendimento contextualizado (NEGRINE, 2010).

Os participantes da pesquisa foram cinco estudantes matriculados no $3^{\circ}$ Ano do EM, em 2017, em uma Escola Estadual de EM do Rio Grande do Sul, localizada na região central de Porto Alegre. Os estudantes eram oriundos de diferentes escolas de Ensino Fundamental, possibilitando que a pesquisa não fosse realizada com base em experiências vividas em uma única escola ou com 
As perspectivas de estudantes ao final da escolarização básica...

Simone Santos Kuhn • Lisandra Oliveira e Silva • Vicente Molina Neto

um único docente de EF, garantindo a representatividade tipológica. Para preservar suas identidades, os participantes receberam nomes fictícios por eles escolhidos: Caio, Elsa, Helena, Moana e Marcela. As aulas de EF das quais participavam no período de realização da pesquisa eram ministradas por dois docentes da escola e por estagiários do Curso de Licenciatura em EF de uma Instituição de Ensino Superior.

Os conhecimentos da pesquisa foram construídos através de um grupo de discussão com os cinco estudantes do Terceiro Ano do EM, da observação participante das aulas de EF desses estudantes, de anotações realizadas em diários de campo e da análise de Documentos da escola pesquisada. A partir do processo de triangulação das informações, apresentamos as três categorias de análise e discussão a seguir.

\section{Conteúdos aprendidos nas aulas de Educação Física na Educação Básica}

Constatamos que os esportes (futsal, vôlei, basquete, handebol e badminton) foram os conteúdos mais presentes durante o período de inserção na escola pesquisada. Para verificar o que ocorreu nas experiências escolares anteriores dos estudantes, perguntamos durante o grupo de discussão sobre os conteúdos que aprenderam nas aulas de EF desde sua entrada na escola. Inicialmente, houve uma manifestação enfática reduzindo os conteúdos aprendidos aos esportes tradicionais: "ISSO É FÁCIL, NÉ! [tom de voz mais alto] Eu fiquei nove anos no Ensino Fundamental, e nesses nove anos eu aprendi quatro coisas: basquete, vôlei, futebol e handebol, e foi isso" (Helena, 31/05/2017). Em seguida, outra contribuição demonstrou algum conhecimento sobre eixos de conteúdos que poderiam ser aprendidos na EF, mas em tom de crítica ao que de fato acontece: 
As perspectivas de estudantes ao final da escolarização básica...

Simone Santos Kuhn • Lisandra Oliveira e Silva • Vicente Molina Neto

[...] os estagiários atuais falaram que na escola era pra gente aprender cinco áreas da EF, que seriam: esportes, dança, lutas e outros dois que eu sinceramente não lembro. Só que não é trabalhado praticamente nada disso, são trabalhados os esportes, e dependendo do caso, se der sorte, outra área (Caio, 31/05/2017).

Os esportes estiveram tão presentes nas experiências escolares desses estudantes, que, em certo momento, Caio chegou a utilizar a palavra esporte como sinônimo de EF. Ele falava sobre a socialização no ambiente escolar, mas, na verdade, quis dizer que ela ocorre em todas as disciplinas escolares. Contudo, para isso, ele utilizou a palavra esporte para referir-se à EF:

Tanto que isso seria um dos pontos do porquê a escola é em turmas, porque a pessoa tem que saber socializar, respeitar, para o futuro lá fora. Isso também serve para o esporte, não tem diferenciação, no caso de matéria ou de qualquer coisa (Caio, 31/05/2017) [grifos nossos].

Além dos Esportes como conteúdos mais vistos na EF, foi possível identificar, no discurso coletivo do grupo, a ênfase nos conteúdos referentes à aptidão física relacionada à saúde. Quando questionado sobre a importância dos conhecimentos adquiridos nas aulas de EF e sobre suas relações com a vida cotidiana, os diálogos se concentraram, principalmente, nos conhecimentos sobre o corpo e nos benefícios dos exercícios físicos para a saúde. Os conteúdos relativos aos conhecimentos sobre o corpo e aos esportes são exemplificados na fala da estudante Elsa, que relata a progressão dos conteúdos ao longo dos anos escolares:

No Fundamental, trabalhamos as partes do corpo humano e como funcionavam. Eu fiz desde a primeira série até a quinta só aula dentro da sala, aprendendo como funcionava, o que podia e não podia fazer. A partir da quinta série foram introduzindo os esportes, eu tive atletismo, judô, e outros esportes diferentes (Elsa, 31/05/2017). 
As perspectivas de estudantes ao final da escolarização básica...

Simone Santos Kuhn • Lisandra Oliveira e Silva • Vicente Molina Neto

Os achados referentes aos conteúdos mais presentes nas aulas de EF na Educação Básica, predominantemente centrados nas práticas esportivas e nos exercícios físicos voltados à saúde, e, repetitivos ao longo dos anos, são semelhantes aos encontrados em outros estudos revisados (CHICATI, 2000; DARIDO, 2004; MATTOS; NEIRA, 2013; FERREIRA; GRAEBNER; MATIAS, 2014; RODRIGUES, 2016). Isso evidencia o quanto as influências dos ideais de promoção da saúde ainda estão presentes, assim como o modelo hegemônico de esportivização, que dominaram a EF escolar no século XX, discutidos por González e Fensterseifer (2009).

Os estudantes também enfatizaram aspectos relacionados ao processo de socialização que está presente na escola. Houve um discurso coletivo sobre a importância das aulas de EF, que, pela característica de proximidade física, inerente às atividades práticas que ocorrem nessas aulas, promove o desenvolvimento da paciência, do respeito às opiniões diversas e da capacidade de compartilhar espaços com outras pessoas, dentre outras habilidades importantes para o convívio em sociedade. Esse discurso pode ser observado na declaração da jovem Elsa:

\begin{abstract}
Eu acho que a gente aprende também a lidar com outras pessoas. Por exemplo, quando eu praticava esportes antes de entrar aqui na escola, era muito estourada, brigava por qualquer coisa. Agora eu aprendi a ter calma, de escutar o professor, de respirar, e aprender que tem outras pessoas na quadra. Por mais que eu não goste de alguém, eu tenho que aprender a respeitar e não sair chutando todo mundo ou agredindo. Acho que tu aprende a ter bons modos, ter educação, nem que seja o básico do básico (Elsa, 31/05/2017).
\end{abstract}

Essas aprendizagens, ligadas ao desenvolvimento da socialização nas aulas de EF, foram mencionadas espontaneamente pelos estudantes, no momento em que discutiam sobre os conteúdos que aprenderam. 


\title{
Os significados da EF escolar e as relações com a vida cotidiana
}

\begin{abstract}
Os estudantes ressaltaram a importância da EF devido à aprendizagem de conteúdos relacionados aos exercícios físicos para manutenção da saúde, citados como relevantes para suas vidas fora da escola. A prevenção do sedentarismo e da obesidade foi o principal argumento utilizado para justificar a importância desses conteúdos. Esse discurso foi identificado em vários momentos da discussão:
\end{abstract}

[...] acho que é importante praticar desde pequeno pra não ficar gordo quando crescer (Elsa, 31/05/2017).

Pra melhorar a nossa forma de vida principalmente por causa desse sedentarismo que tem hoje em dia (Helena, 31/05/2017).

Seríamos dez vezes mais sedentários do que muitos são. Hoje em dia há um sedentarismo alto pra muitas pessoas (Caio, 31/05/2017).

Entre os conteúdos aprendidos nas aulas de EF durante a Educação Básica, foi identificada a predominância dos conteúdos relacionados aos exercícios físicos voltados para a manutenção da saúde, o que poderia justificar a maior tendência a relacioná-los com a vida cotidiana e a considerá-los importantes. No entanto, o mesmo não ocorreu com os esportes, que foram igualmente citados como conteúdos mais vistos, mas não foram enfatizados no momento de identificação com a vida fora da escola.

Quando perguntado se já haviam participado de práticas corporais fora do ambiente escolar, em decorrência do interesse despertado pelos conteúdos vistos nas aulas de EF, duas jovens responderam que sim. Uma delas se envolveu com as práticas do judô e da musculação, e, a outra, com a prática do futebol. Ambas afirmaram que conheceram essas práticas corporais nas aulas de EF na escola, e que foram essas experiências que motivaram sua 
As perspectivas de estudantes ao final da escolarização básica...

Simone Santos Kuhn • Lisandra Oliveira e Silva • Vicente Molina Neto

busca por participação fora do ambiente escolar. Nesse contexto, foi destacada a importância do acesso a diversas práticas corporais nas aulas de EF, que não seria possível em outro local fora do ambiente escolar, pela falta de recursos financeiros e de segurança para realizá-las por conta própria:

Eu acho que tem que ter na escola porque muita gente não tem acesso, tem gente que mora em bairros que são muito pobres e não tem acesso a uma quadra, e eles não vão sair assim, sei lá, pra correr, com o risco de levar um tiro na rua sabe? Então, acho que o colégio é um lugar meio confortável pra poder praticar os exercícios, e seguro sabe? (Elsa, 31/05/2017).

Esse argumento para justificar a importância da EF na escola é semelhante ao que foi utilizado por outro estudante durante uma aula de EF e foi registrado em diário de campo. O estudante manifestou o desejo de que os esportes aprendidos nas aulas de EF fossem praticados na própria escola, devido às dificuldades de acesso para a prática fora dela.

Toda a ênfase dada pelos estudantes aos conteúdos ligados aos esportes e à prática de exercícios físicos, também foi observada no Projeto Político Pedagógico (PPP) da escola pesquisada. Nesse documento, a EF foi diretamente ligada aos espaços da quadra e do ginásio, com indicação de finalidade voltada às práticas de esportes e de exercícios físicos. Dessa forma, os sentidos atribuídos à EF, em grande parte, estavam atrelados a esses conteúdos, sendo um reflexo dos princípios pedagógicos presentes na cultura escolar em questão.

Para Oliveira, Silva e Molina Neto (2011), os espaços da escola e os recursos materiais dos quais os professores de EF dispõem expressam uma determinada concepção educativa e refletem a associação entre o ambiente e a sua função. Sobre isso, os autores destacam que: 
As perspectivas de estudantes ao final da escolarização básica...

Simone Santos Kuhn • Lisandra Oliveira e Silva • Vicente Molina Neto

[...] desde a forma de construção até a localização dos espaços, tudo é delimitado formalmente de acordo com princípios pré-estabelecidos, que enunciam uma expectativa de comportamento das pessoas que usufruem desses locais. Neste sentido, a arquitetura escolar interfere na forma de circulação dos indivíduos, e na definição das funções para cada ambiente (OLIVEIRA; SILVA; MOLINA NETO, 2011, p. 5).

Um exemplo que consta nos diários de campo da pesquisa e que ilustra os exercícios físicos compreendidos como finalidade da EF na escola descreve as ações de duas estudantes do $3^{\circ}$ Ano do EM. No horário em que deveriam estar na aula de EF, as jovens dedicavam-se ao que parecia ser um treinamento físico. Por vezes, corriam ao redor da quadra enquanto a aula de EF ocorria. Em outras ocasiões, faziam exercícios de força e de potência muscular. Ao investigarmos o motivo de tais práticas, soubemos que se tratava de uma preparação para testes físicos, pois participariam de processo seletivo para ingresso no Exército Brasileiro. Ao que parecia, essas meninas e os docentes consideravam que a prática de exercícios físicos substituía satisfatoriamente a participação nas aulas de EF.

Outro elemento abordado pelos estudantes foi a contextualização dos conteúdos das aulas de EF com a vida diária. Os jovens consideraram-na fundamental para que os conteúdos fossem significativos, ao falarem das aulas dos estagiários de EF:

\footnotetext{
A EF ano passado foi pra levar pra vida mesmo (Marcela, 31/05/2017).

É, foi muito mais escrito, a gente fazia vários bagulhos né? Tipo de escrever (Moana, 31/05/2017).

A gente tinha conversa sobre isso (Helena, 31/05/2017).

Conversa, a gente fazia a aula daí depois ele [estagiário] perguntava no que isso ajudou (Moana, 31/05/2017).

Pra que isso serve? (Helena, 31/05/2017).
} 
As perspectivas de estudantes ao final da escolarização básica...

Simone Santos Kuhn • Lisandra Oliveira e Silva • Vicente Molina Neto

A importância da contextualização dos conteúdos das aulas de EF segundo o entendimento de estudantes do EM também foi verificada nos estudos de Frey (2007) e de Ferreira, Graebner e Matias (2014). Nesses estudos, o tema foi abordado a partir das críticas dos estudantes à falta de contextualização, que implicava na não participação das aulas, pois a prática pela prática não fazia sentido para eles. Na presente pesquisa, a relevância da contextualização nas aulas de EF não foi discutida pela ausência, mas a partir de relatos das experiências dos estudantes nas aulas dos estagiários que atuavam na escola pesquisada. As práticas pedagógicas desses professores em processo de "Formação Inicial" foram determinantes para que os estudantes conhecessem uma EF contextualizada e para que percebessem novos significados para essa disciplina na escola.

\section{As aulas de EF como espaço de relações interpessoais no ambiente escolar}

As aulas de EF foram consideradas um espaço de sociabilidade entre os jovens, que, segundo eles, a estrutura escolar não proporciona em muitos momentos. Os estudantes relataram algumas dificuldades enfrentadas devido à maneira como a escola pesquisada estava organizada, a saber, em salas ambientes. Para eles, isso fazia com que os intervalos para trocas entre períodos de aulas fossem consumidos apenas com os deslocamentos necessários, impedindo momentos importantes de interação, como pode ser verificado na fala de Helena: "Então aquele momento ali que a gente teria pra respirar, pra conversar com o outro, a gente perde, a gente tem que ficar correndo atrás de professor [...]" (Helena, 31/05/2017).

A crítica dos estudantes ao modo de organização da escola demonstra a importância de todo o tempo em que estão na escola. O prejuízo relatado não se refere ao tempo perdido com os deslocamentos em si, mas à perda em termos de possibilidades de 
As perspectivas de estudantes ao final da escolarização básica...

Simone Santos Kuhn • Lisandra Oliveira e Silva • Vicente Molina Neto

relacionamentos que gostariam de estabelecer nesses momentos. Dayrell e Carrano (2014) explicam que a sociabilidade nessa fase da vida tende a ocorrer em um fluxo cotidiano em locais e momentos diversos, e, inclusive, nos intervalos entre as obrigações:

\begin{abstract}
A sociabilidade [...] pode ocorrer no interior das instituições, seja no trabalho ou na escola, na invenção de espaços e de tempos intersticiais, recriando um momento próprio de expressão da condição juvenil nos determinismos estruturais (DAYRELL; CARRANO, 2014, p. 118).
\end{abstract}

Nesse contexto, as aulas de EF foram indicadas como o espaço no qual a sociabilidade é facilitada no ambiente escolar. A possibilidade de conhecer e de dialogar com outras pessoas foi apontada como um fator importante. Duas participantes da pesquisa citaram o exemplo de que, apesar de estudarem diariamente na mesma turma, conversaram pela primeira vez durante uma aula de EF: “É que a gente pode interagir. Por exemplo, eu nunca tinha falado com a Marcela até ter EF, aí sei lá, eu comecei a falar com ela, nem que seja o mínimo" (Elsa, 31/05/2017).

Caio também exemplificou que as práticas esportivas que ocorrem nas aulas de EF são facilitadoras para que novas relações interpessoais se estabeleçam entre os estudantes. Ele explicou que quando essas práticas são realizadas fora do ambiente escolar, geralmente, ocorrem entre amigos, e que há uma tendência de agirem de acordo com um padrão já conhecido. No entanto, quando ocorrem nas aulas de EF na escola, além do ambiente de aula proporcionar novas aprendizagens, devido às ações pedagógicas do professor, as interações com os colegas, que em outros momentos são mais distantes, permitem conhecê-los melhor.

As colocações dos estudantes se relacionam com as teorizações de Dayrell e Carrano (2014, p.118), ao afirmarem que: "a sociabilidade para os jovens parece responder às suas necessidades de comunicação, de solidariedade, de democracia, de autonomia, de trocas afetivas e, principalmente, de identidade". Nesse con- 
As perspectivas de estudantes ao final da escolarização básica...

Simone Santos Kuhn • Lisandra Oliveira e Silva • Vicente Molina Neto

texto, quando falam em identidade, os autores a consideram uma relação social, uma interação "que aponta para a importância do pertencimento grupal e das suas relações solidárias para o reforço e a garantia da identidade individual" (DAYRELL; CARRANO, 2014, p. 123). Assim, quando os estudantes discutiram sobre suas necessidades de interação social na escola e enfatizaram a importância das aulas de $\mathrm{EF}$, falaram de processos que envolvem a construção das suas identidades, e do quanto essa disciplina contribui para isso.

Apesar dos aspectos positivos ressaltados nas aulas de EF, em termos de sociabilidade, uma forte crítica foi direcionada à separação dessas aulas de acordo com o sexo na escola pesquisada:

Eu não gosto dessa separação, porque no Fundamental eu sempre tive aula junto com os guris e o meu relacionamento com os meus colegas era muito melhor, eles aprendiam a respeitar mais a gente entendeu? (Helena, 31/05/2017).

[...] a separação das duas turmas, masculina e feminina, não faz o menor sentido, eu sinceramente não sei qual é o fundamento disso (Caio, 31/05/2017).

Em alguns momentos, os estudantes chegaram a evidenciar a existência de aulas de EF diferentes: "[...] depende de qual EF tu faz, de como é a tua EF, depende muito de como a aula se desenvolve, como ela funciona, como os professores propõem a aula" (Caio, 31/05/2017). Quando Caio afirmou que existem aulas de EF diferentes, referia-se à separação por sexo. Pouco depois dessa fala, ele abordou novamente o assunto de maneira mais direta, demonstrando que queria debater o assunto: “[...] só que uma grande diferença do Fundamental para o Médio, que é uma coisa que eu de início não entendi, é a separação das turmas masculinas e femininas" (Caio, 31/05/2017). Essa provocação levou ao posicionamento das demais participantes sobre o tema, de maneira que as meninas passaram a relatar algumas experiências frustrantes vividas nas aulas de EF: 
As perspectivas de estudantes ao final da escolarização básica...

Simone Santos Kuhn • Lisandra Oliveira e Silva • Vicente Molina Neto

Eu também não concordo com essa separação porque até o nosso professor [...] falava na nossa cara: - Vocês são frágeis, vocês não vão jogar futebol e é isso, vão jogar vôlei e se contentem com isso! Basicamente, e eu não entrava na aula de EF, era uma revolta, uma revolta (Elsa, 31/05/2017).

E a gente tinha que fazer vôlei porque ele dizia que era um esporte fácil (Helena, 31/05/2017).

Aí ele largava a bola, a gente tinha que jogar e se contentar com isso, aí acho que a maioria das gurias começaram a não ir na aula, a ir sem uniforme já pra não fazer (Elsa, 31/05/2017).

O fato da separação das aulas por sexo ter sido abordada e criticada espontaneamente pelos estudantes demonstrou que se trata de um assunto que lhes provoca contrariedades e inquietações.

Ainda no tocante às relações interpessoais no ambiente escolar, ressaltamos a temática do vínculo entre professores e estudantes. No PPP da escola, havia preocupação com algumas dificuldades nos relacionamentos dos docentes para com os estudantes que constavam em uma lista de desafios a serem superados. Dentre essas dificuldades, foi citada a falta de vínculos na escola e de habilidades para compreender a juventude atual e para lidar com os estudantes. Conforme constava nesse documento, tais fatores contribuíam para o baixo desempenho nos estudos, pois os jovens necessitavam de atenção e de afeto.

Registramos algumas impressões sobre o distanciamento dos professores em relação aos estudantes. Um exemplo que pode ser citado diz respeito ao que ocorreu durante uma aula de EF, quando uma funcionária da escola chegou para entregar os boletins com os conceitos das avaliações dos estudantes, como se fosse um mero procedimento burocrático, sem importância pedagógica. Apesar de cada turma ter um professor conselheiro, os boletins eram entregues dessa forma, por alguém que não tinha relação alguma com as avaliações dos estudantes. 
As perspectivas de estudantes ao final da escolarização básica...

Simone Santos Kuhn • Lisandra Oliveira e Silva • Vicente Molina Neto

Os participantes da pesquisa afirmaram que, com algumas exceções, os professores não davam atenção aos interesses dos estudantes "porque achavam que a matéria é mais importante do que o desenvolvimento dos alunos" (Caio, 31/05/2017). Essa crítica foi estendida ao ambiente criado nas aulas da maioria das disciplinas, sendo destacado pelos jovens que eles têm mais interesse pelos conteúdos quando as aulas são mais descontraídas e quando o professor age espontaneamente, conversando sobre assuntos variados e fazendo algumas brincadeiras.

No diálogo a seguir, pode ser observada a importância atribuída pelos estudantes ao diálogo e ao vínculo com os professores, e o quanto isso influencia no interesse pelas aulas:

A gente não tinha espaço pra conversar. Os estagiários [de EF], pelo menos os que a gente teve, se interessavam pela gente: Fala um pouquinho o que aconteceu no final de semana. Eles contam também da vida deles entendeu? Então é um espaço que a gente aprende, a gente se exercita, mas a gente tem aquele diálogo sabe? (Helena, 31/05/2017).

Eu acho que com os estagiários [de EF] quebrou um pouco dessa barreira aluno-professor, a gente está todo mundo ali pra mesma coisa, estamos aí vamos conversar né? Vamos ser amigos, essas coisas (Elsa, 31/05/2017).

É que eles são alunos também, né? (Marcela, 31/05/2017).

É! E eles têm, sei lá, no máximo vinte e cinco anos, eles estão numa idade próxima da gente, sabem o que é o EM, o que a gente está passando (Elsa, 31/05/2017).

E eles sabem nossos nomes! De todo mundo! (Moana, 31/05/2017).

É, isso é muito importante, eles não chamam a gente de guriazinha (Elsa, 31/05/2017).

Eu acho que isso melhora muito a relação, eu prefiro muito ir pra uma aula que o professor sabe o nosso nome, conhece a gente sabe? (Moana, 31/05/2017). 
As perspectivas de estudantes ao final da escolarização básica...

Simone Santos Kuhn • Lisandra Oliveira e Silva • Vicente Molina Neto

Na pesquisa de Abramovay, Castro e Waiselfisz (2015), realizada com estudantes do EM, foram encontrados relatos semelhantes aos dos estudantes participantes da presente pesquisa, no que se referem às suas percepções quanto à importância das relações entre estudantes e professores. Foi apontado que as práticas pedagógicas dos professores são fundamentais para o aprendizado e para que os jovens frequentem as aulas, uma vez que, segundo eles, os bons professores são aqueles que sabem brincar, conversar, interagir; incentivam a aprender; dão boas aulas e trabalhos interessantes; respondem as dúvidas; e sabem prender a atenção dos estudantes (ABRAMOVAY; CASTRO; WAISELFISZ, 2015).

A cobrança dos docentes quanto aos estudos para o vestibular foi enfatizada pelos estudantes como um exemplo do quanto sentem falta do diálogo e do auxílio dos professores, pois esse é um motivo de dúvidas e de inquietações quanto ao futuro próximo. Os jovens relataram que gostariam de receber orientação quanto à indecisão para a escolha dos cursos de graduação, bem como sobre a possibilidade de não conseguirem a aprovação no vestibular:

E eu acho que principalmente porque a gente tá no $3^{\circ}$ Ano, a gente tem que estudar, estudar. Eles têm que dar matéria, matéria. Então, eles não vão ceder um período só pra gente conversar sobre assuntos, eles tem que passar a matéria pra gente passar no vestibular (Moana, 31/05/2017).

Mas o que acontece depois do vestibular? Eles nunca pensam nisso, né? Porque eu estou pensando em não fazer o Enem porque eu não sei que faculdade eu quero fazer, eu estou entre cinco, e aí eu não sei, e eu estou pensando: vou cancelar isso aí e não vou fazer. Eu não sei o que vou fazer da minha vida, e acho que preciso de um mínimo de auxílio sabe? Acho que é importante (Elsa, 31/05/2017).

E nenhum adulto fala desse negócio de vestibular, ninguém pega e fala, todo mundo só fala pra gente passar, passar, passar, isso e aquilo, mas ninguém fala: tá, tu faz e aí tu não passa e tu fica praticamente um ano a nada, entendeu? (Helena, 31/05/2017). 
As perspectivas de estudantes ao final da escolarização básica...

Simone Santos Kuhn • Lisandra Oliveira e Silva • Vicente Molina Neto

A separação do ambiente das aulas e do ambiente para conversas sobre assuntos do contexto de vida dos estudantes foi marcante nas falas dos jovens. Quando disseram que gostariam de ter espaços na escola para falarem de assuntos importantes para eles, remeteram para um espaço separado das aulas, como um período cedido para isso, ou para um profissional especialista, como um psicólogo para conversar. Nesse contexto, o Serviço de Orientação Educacional da escola foi apontado como inoperante e voltado apenas para situações graves de conflitos. Sendo que, conforme Abramovay, Castro e Waiselfisz (2015), muitos conflitos e problemas que ocorrem nas escolas são decorrentes do descompasso entre a cultura escolar e a cultura juvenil, bem como da falta de sensibilidade pelas maneiras de ser dos jovens e por como privilegiam a comunicação.

Assim, a necessidade dos jovens de serem ouvidos e considerados no debate escolar ficou evidente nos achados da pesquisa. Para Dayrell e Carrano (2014, p. 127), escutar a si e ao outro é a condição para o reconhecimento e para a comunicação, uma vez que "propiciar espaços-tempos educativos e promover processos de aprendizagem para que os sujeitos reconheçam a si mesmos e aos outros deveria ser meta prioritária das instituições escolares". $\mathrm{Na}$ escola pesquisada, mesmo com as dificuldades que os jovens apresentaram para falarem de assuntos de seus interesses nas aulas, a EF, pelos vínculos que vêm sendo estabelecidos entre os estudantes, alguns docentes e os estagiários, tem demonstrado um grande potencial para aproximação dos estudantes com a instituição escolar.

\section{Considerações Transitórias}

No percurso de construção dos conhecimentos desenvolvido na pesquisa, os significados atribuídos pelos estudantes do $3^{\circ}$ Ano do EM às suas experiências nas aulas de EF durante a Educação 
As perspectivas de estudantes ao final da escolarização básica...

Simone Santos Kuhn • Lisandra Oliveira e Silva • Vicente Molina Neto

Básica foram analisados e discutidos nas três categorias apresentadas anteriormente, e os achados podem ser assim sintetizados:

(a) Os conteúdos aprendidos pelos estudantes nas aulas de EF foram: esportes; lutas; conhecimentos sobre o corpo, suas possibilidades e seus limites; exercícios físicos para a manutenção da saúde; e desenvolvimento da socialização.

(b) Os conteúdos mais relacionados com a vida cotidiana dos estudantes foram os conhecimentos sobre os exercícios físicos para manutenção da saúde.

(c) O acesso a diversas práticas corporais nas aulas de EF foi importante, devido à falta de recursos financeiros e de segurança para realizá-las em outros locais.

(d) A contextualização dos conteúdos das aulas de EF foi fundamental para que fossem significativos para os estudantes.

(e) As aulas de EF foram consideradas um espaço de sociabilidade entre os jovens, que, segundo eles, a estrutura escolar não proporcionava em muitos momentos.

(f) Houve crítica à separação das aulas de EF de acordo com o sexo na escola pesquisada, pois, além de prejudicar o relacionamento entre meninos e meninas, não tinha sentido para os estudantes.

(g) O diálogo e o vínculo interpessoal com alguns docentes da escola e com os estagiários de EF foram fatores fundamentais para a participação nas aulas de EF e para que os conteúdos fossem mais interessantes e mais significativos.

(h) As opiniões e o engajamento dos estudantes no grupo de discussão demonstraram a necessidade dos jovens de serem ouvidos na escola.

Assim, ao dialogarmos com os estudantes aprendemos, dentre outros elementos, que mais importante do que os conteúdos que o professor ensina é o caminho pelo qual escolhe ensinar. Esse caminho, conforme indicaram os jovens participantes da pesquisa, precisa levar na direção da valorização do estudante, da 
As perspectivas de estudantes ao final da escolarização básica...

Simone Santos Kuhn • Lisandra Oliveira e Silva • Vicente Molina Neto

contextualização e da humanização das práticas pedagógicas no ambiente escolar.

\section{Referências}

ABRAMOVAY, Miriam; CASTRO, Mary Garcia; WAISELFISZ, Júlio Jacobo. Juventudes na escola, sentidos e buscas: Por que frequentam? 1. ed. Brasília: FLACSO, Brasil, OEI, MEC, 2015.

CARRANO, Paulo. A participação social e política de jovens no Brasil: considerações sobre estudos recentes. O Social em Questão, Rio de Janeiro, ano XV, n. 27, p. 83-99, 2012.

CHICATI, Karen Cristina. Motivação nas aulas de educação física no ensino médio. Revista da Educação Física/UEM, Maringá, v. 11, n. 1, p. 97-105, 2000.

DARIDO, Suraya Cristina. A educação física na escola e o processo de formação dos não praticantes de atividade física. Revista Brasileira de Educação Física e Esporte, São Paulo, v. 18, n. 1, p. 61-80, jan./mar., 2004.

DAYRELL, Juarez; CARRANO, Paulo. Juventude e Ensino Médio: quem é este aluno que chega à escola. In: DAYRELL, Juarez; CARRANO, Paulo; MAIA, Carla Linhares (Orgs.). Juventude e Ensino Médio: sujeitos e currículos em diálogo. Belo Horizonte: Editora UFMG, 2014. p. 101-133.

FERREIRA, Mayara Luana dos Santos; GRAEBNER, Luciane; MATIAS, Thiago Sousa. Percepção de alunos sobre as aulas de Educação Física no Ensino Médio. Pensar a Prática. Goiânia, v. 17, n. 3, p. 734-750, jul./set. 2014.

FREY, Mariana Camargo. Educação Física no Ensino Médio: A opinião dos alunos sobre as aulas. EFDeportes.com, Revista Digital. Buenos Aires, ano 12, n. 113, out. 2007. Disponível em: http:// www.efdeportes.com/. Acesso em: 20 nov. 2016. 
As perspectivas de estudantes ao final da escolarização básica...

Simone Santos Kuhn • Lisandra Oliveira e Silva • Vicente Molina Neto

MATTOS, Mauro Gomes de; NEIRA, Marcos Garcia. Educação

Física na Adolescência: construindo o conhecimento na escola.

6. ed. São Paulo, Phorte, 2013.

NEGRINE, Airton. Instrumentos de coleta de informações na pesquisa qualitativa. In: MOLINA NETO, Vicente; TRIVIÑOS, Augusto Silva (Orgs.). A Pesquisa Qualitativa na Educação Física:

Alternativas Metodológicas. Porto Alegre, Sulina, 2010. p. 61-99.

OLIVEIRA, Camila Fagundes de; SILVA, Lisandra Oliveira e; MOLINA NETO, Vicente. Arquitetura escolar e o ensino de Educação Física: relações (im) possíveis. Pensar a prática. Goiânia, v. 14, n. 2, p. 1-10, maio/ago., 2011.

RODRIGUES, Thiago Fernandes. Os significados da Educação Física na perspectiva dos estudantes do Ensino Médio:

um estudo de caso em uma escola de Porto Alegre. 2016. 51

p. Trabalho de Conclusão de Curso (Graduação) - Escola de Educação Física, Fisioterapia e Dança, Universidade Federal do Rio Grande do Sul, Porto Alegre, 2016.

SILVA, Lisandra Oliveira; MOLINA NETO, Vicente. Os sentidos da escola e da Educação Física para estudantes e docentes de uma rede pública municipal. Movimento. Porto Alegre, v. 20, n. 3, p. 1139-1158, jul./set., 2014.

\section{Financiamento}

A presente pesquisa teve financiamento do Programa Institucional de Bolsas de Iniciação Científica/Conselho Nacional de Desenvolvimento Científico e Tecnológico. 


\section{Aprovação de comitê de ética em pesquisa}

Pesquisa aprovada pelo Comitê de Ética da Universidade Federal do Rio Grande do Sul. Título: A Educação Física no Ensino Médio: Estudos de Casos na Rede Estadual de Ensino do Rio Grande do Sul.

\section{Publisher}

Universidade Federal de Goiás. Faculdade de Educação Física e Dança. Publicação no Portal de Periódicos UFG. As ideias expressadas neste artigo são de responsabilidade de seus autores, não representando, necessariamente, a opinião dos editores ou da universidade. 